ARTICLE

\title{
Recommendations for the use of immunoglobulin therapy for immunomodulation and antibody replacement
}

J G Peter, ${ }^{1}$ MB ChB, MMed, FCP (SA), PhD; J M Heckmann, ${ }^{2}$ MB BCh, MMed, FCN (SA), PhD;

N Novitzky, ${ }^{3}$ PhD, Dip Med, FCP (SA), Cert Clin Haematol (SA)

${ }^{1}$ Division of Immunology, Department of Medicine, Faculty of Health Sciences, University of Cape Town, South Africa

${ }^{2}$ Division of Neurology, Department of Medicine, Faculty of Health Sciences, University of Cape Town, South Africa

${ }^{3}$ Division of Haematology, Department of Medicine, Faculty of Health Sciences, University of Cape Town, South Africa

Corresponding author: J G Peter (jonny.peter@uct.ac.za)

\begin{abstract}
Polyvalent immunoglobin, derived from pooled human plasma, can be administered via the intravenous, subcutaneous or intramuscular route. Therapy is standard of care in the treatment of a number of immune-mediated pathologies across disciplines. By volume, the majority is used in neurology $(\sim 40 \%)$. In primary immunodeficiencies, therapy reconstitutes humoral immunity at replacement doses $(0.4-0.6 \mathrm{~g} /$ $\mathrm{kg} / \mathrm{month}$ ), decreasing infections, and is usually lifelong. However, high doses, usually $2 \mathrm{~g} / \mathrm{kg}$ total dose over five days, are required for immunomodulation in autoimmune and inflammatory indications. A high-quality evidence base supports use in primary antibody failure, Guillain-Barré syndrome, chronic inflammatory demyelinating polyneuropathy, acute idiopathic thrombocytopenia, Kawasaki disease and immunobullous diseases. Low-quality evidence shows benefit in many other uncommon autoimmune and immunodeficient conditions. In South Africa, use of immunoglobulin therapy is restricted and, given the cost involved, will likely remain so. Therefore, the incremental benefit over other forms of immunosuppression, particularly corticosteroids, must be assessed carefully on a case-by-case basis. In most cases, therapy will be second-line or 'rescue' and motivation will be required. This short review aims to provide clinicians with the necessary understanding of the therapy, general considerations for use, and evidence base and quality thereof for well-established indications.
\end{abstract}

S Afr Med J 2014;104(11):796. DOI:10.7196/SAMJ.8965

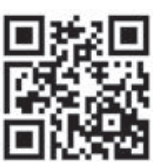

The practice of treating diseases with serum is over 100 years old. Unfortunately, variable efficacy, poor safety and inadequate understanding of the actions of specific serum components limited early use. Modern advances in fractionation and filtration technologies since the late 1940s led to the development of increasingly safer and pure immunoglobulin preparations. Currently, they are used worldwide to treat a number of immune- mediated pathologies (Table 1). The use of immunoglobulin therapy in South Africa (SA) is restricted, and will likely remain so, given the cost involved. The incremental benefit over other forms of immunosuppression must be assessed carefully to justify the additional expense. Clinicians should have an understanding of the therapy, considerations for use and evidence-based quality of data in specific disciplines. In this review we discuss these in the context of current use in SA.

Table 1. Current major uses and grade of evidence for immunoglobulin therapy

\begin{tabular}{|c|c|c|c|}
\hline Neurology & Haematology & Immunology & Other \\
\hline Guillain-Barré syndrome $(\mathrm{A})^{*[5]}$ & $\begin{array}{l}\text { Immune thrombocytopenic purpura (RCT, } \\
\text { limited evidence in chronic ITP) (A) }\end{array}$ & $\begin{array}{l}\text { Primary antibody } \\
\text { deficiencies }(\mathrm{A})^{[33,45]}\end{array}$ & Kawasaki disease $(\mathrm{A})^{[39]}$ \\
\hline $\begin{array}{l}\text { Chronic inflammatory demyelinating } \\
\text { polyradiculoneuropathy }(\mathrm{A})^{[6]}\end{array}$ & $\begin{array}{l}\text { Alloimmune thrombocytopenia (feto- } \\
\text { maternal/neonatal) }\end{array}$ & $\begin{array}{l}\text { Specific antibody deficiency } \\
\text { (GPP) }\end{array}$ & $\begin{array}{l}\text { Toxic epidermal } \\
\text { necrolysis, Stevens- } \\
\text { Johnson syndrome (no } \\
\text { mortality benefit) }\end{array}$ \\
\hline Multifocal motor neuropathy (GPP) $)^{[7]}$ & Haemolytic disease of the newborn & $\begin{array}{l}\text { Secondary antibody } \\
\text { deficiency (including } \\
\text { myeloma, CLL (RCT), drugs } \\
\text { and other causes) (GPP) }{ }^{[46]}\end{array}$ & $\begin{array}{l}\text { Immunobullous disease } \\
(\mathrm{A})^{[37]}\end{array}$ \\
\hline \multicolumn{4}{|l|}{ Myasthenia gravis (GPP) ${ }^{[13]}$} \\
\hline Dermatomyositis/polymyositis $(\mathrm{GPP})^{[14]}$ & Autoimmune haemolytic anaemia (GPP) & & \\
\hline Autoimmune limbic encephalitis ${ }^{\dagger}(\mathrm{GPP})^{[17]}$ & Post bone marrow transplantation (A) & & \\
\hline Stiff person syndrome ${ }^{[16]}$ & Parvovirus B19-associated aplasia & & \\
\hline
\end{tabular}




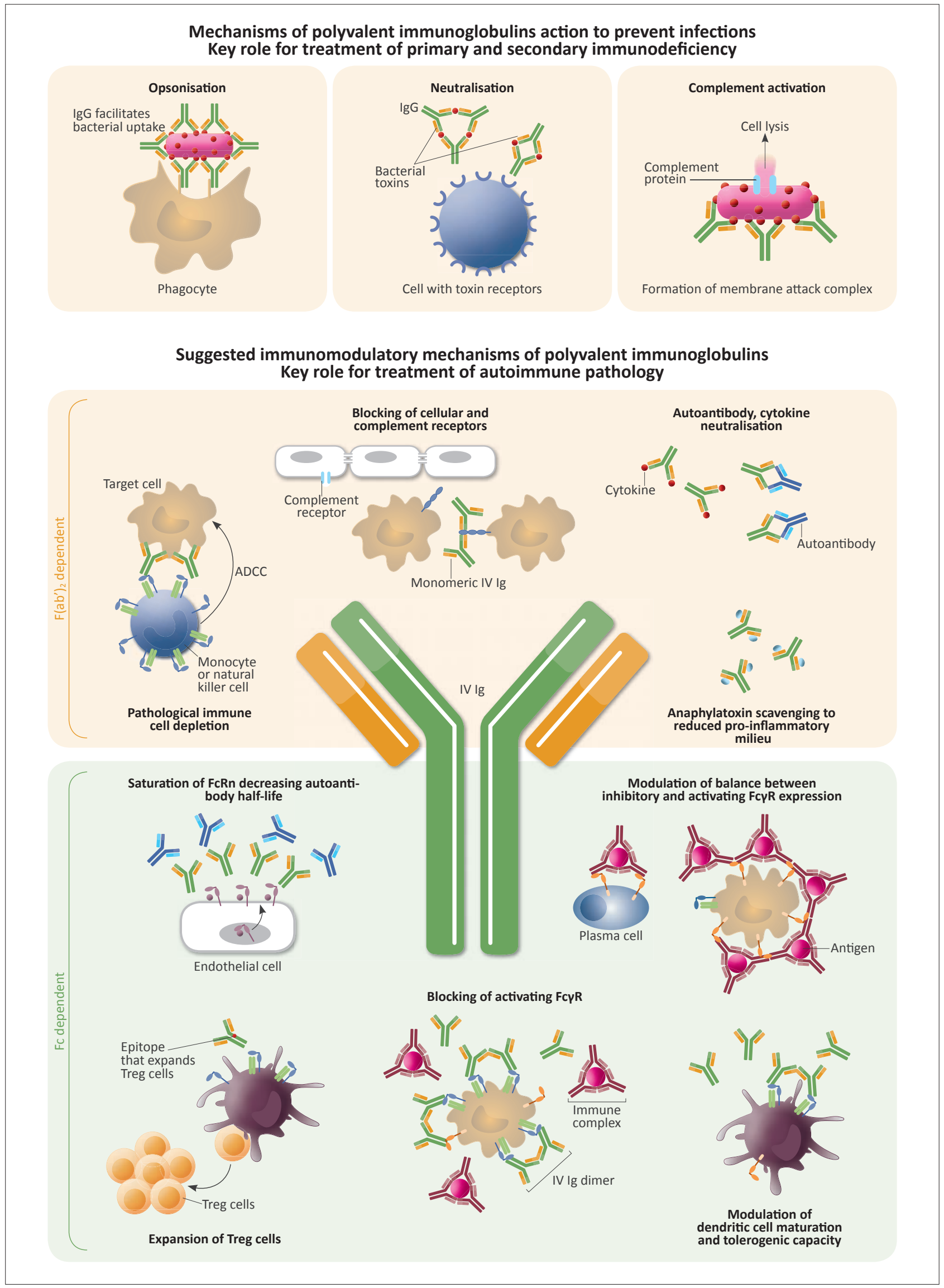

Fig. 1. Established and proposed mechanism of action for immunoglobulin therapy (ADCC = antibody-dependent cell-mediated cytotoxicity; FcRn = FC neonatal receptor; $F c \gamma R=F c y$ receptor $;$ IgG = immunoglobulin $G ;$ IV Ig = intravenous immunoglobulin; Treg cells = regulatory T cells.) 


\section{Immunoglobulin therapy: General considerations}

Polyvalent immunoglobulin is purified from pooled human plasma. This origin as a plasma product underpins the majority of general considerations, both advantages and disadvantages.

\section{Manufacture and available preparations}

Fractionation of immunoglobulin from donor plasma, removing unwanted and/or infectious substances and stabilising and packaging it for remote clinical use, is a laborious and expensive process. Only four registered products are available in SA (Table 2). Immunoglobulin preparations are available for intravenous (IV), intramuscular (IM) and subcutaneous (SC) administration, with concentrations between $2 \%$ and $16 \%$. SC administration is increasingly used for both immunomodulation (high dose) and replacement therapy. Product differences warranting clinical considerations, highlighted for SA products in Table 2, include varying immunoglobulin (Ig) A content, different stabilising sugars/amino acids, storage conditions and cost.

\section{Mechanisms of action}

The pooling of antibodies from thousands of donors provides a diversity of antibody repertoires and specificities. Fig. 1 outlines proposed mechanisms of actions. In immunodeficiency, antibody replacement therapy reconstitutes fundamental humoral immunity. Immunomodulatory mechanisms of action are less well understood and are likely to differ, depending on the specific autoimmune pathogenesis and individual genetic background. Diseases responding rapidly, but with short-lived duration of efficacy, suggest that high serum levels of therapeutic IgG 'neutralise' pathogenic autoantibodies. ${ }^{[1]}$ Other proposed mechanisms include binding or blocking of the antigen-binding site (anti-idiotype), enhancing IgG turn-over, thereby reducing circulating pathogenic IgG, as well as scavenging circulating complement binding sites and interfering with activation of the complement cascade. ${ }^{[1]}$ Two excellent reviews discuss the immunomodulatory mechanism of action in greater depth. ${ }^{[2,3]}$

\section{Side-effects}

The major side-effects of immunoglobulin preparations are summarised in Table 3. Immediate infusion-related reactions occur in about $1 \%$ of all IV Ig infusions, but are usually mild and can be treated symptomatically with simple analgesia. Moderate reactions can be treated with antihistamines or corticosteroids. Reactions usually relate to intercurrent infections or over-rapid administration and can be avoided with brief clinical review prior to therapy, slow initiation of therapy and adherence to manufacturers' suggested infusion rates. However, the more serious side-effects are associated with high-dose IV Ig and relate to the up to fourfold increase in serum IgG and additional plasma proteins. One needs to monitor for renal impairment, which is usually reversible. Pre-hydration is important and it is preferable to use an IV preparation without sugars or the SC route of administration in patients with pre-existing renal disease or the elderly. Unfortunately, the choice of product options is currently limited in SA.

\section{Therapeutic use: Evidence and current application in SA}

Immunoglobulin use is supported by high-quality evidence (randomised control trials (RCTs)) for certain conditions in neurology, haematology, immunology and dermatology (Table 1). In addition, Ig therapy is used off-label, and with limited evidence, for a wide array of other diseases with immunopathology, usually after the failure of first-line therapies. ${ }^{[4]}$ Globally, and in SA, the largest volume of Ig is used by neurology $(\sim 40 \%)$, followed by haematology. In immunodeficiencies, immunoglobulin replacement is used in lower volumes but therapy tends to be lifelong. The high cost of therapy and lack of availability limit use worldwide, but in SA, especially in the public sector, this affects use - even for conditions with wellestablished benefit. In the sections below we outline the evidence by discipline. Table 4 provides important general considerations and practice points prior to commencing immunoglobulin therapy.

\section{Neurology}

Ig therapy is highly effective in a number of neuromuscular diseases, but the substantial cost must be considered in developing a treatment plan. The mechanism of action of Ig in different diseases may vary and therefore appropriate dosing and frequency of administration may differ. ${ }^{[1]}$ Cochrane reviews provide good evidence that recovery in severe Guillain-Barré syndrome is hastened if IV Ig $(0.4 \mathrm{~g} / \mathrm{kg}$ for 5 days) or plasma exchange are started within the first two weeks of symptom onset. ${ }^{[5]}$ There is no evidence that giving IV Ig after plasma exchange provides additional benefit. In chronic inflammatory demyelinating polyradiculoneuropathy (CIDP), IV Ig (one course, total dose $2 \mathrm{mg} / \mathrm{kg}$ ) is superior compared with no treatment in inducing improvement within six weeks; for every three persons treated with IV Ig, one improved. However, similar clinical benefits were obtained at two and six weeks when IV Ig was compared with plasma exchange or corticosteroids (prednisone or IV methylprednisolone). ${ }^{[6]}$ Despite limited data, one trial showed sustained benefit for 24 and 48 weeks using IV Ig compared with placebo. ${ }^{[6]}$ Compared with IV methylprednisolone $(0.5 \mathrm{~g} \times 4$ days, monthly), those receiving monthly courses of Ig for CIDP were less likely to discontinue owing to lack of efficacy or intolerance, but were more likely to worsen after discontinuation at 6 months. ${ }^{[6]}$ Overall, current evidence suggests that either IV Ig or corticosteroids should be considered as first-line treatment for CIDP. If doses of the aforementioned induction treatment are required to remain high to maintain disease control, an additional immunosuppressant or immunomodulating treatment should be considered. In the rare case of multifocal motor neuropathy (MMN) that does not respond to prednisone or plasma exchange, IV Ig therapy should be considered based on limited evidence; however, not all patients show substantial responses and ongoing therapy should be re-evaluated regularly. ${ }^{[7]}$ Based on limited evidence, IV Ig resulted in a modest, short-term benefit in IgM anti-myelin-associated glycoprotein paraproteinaemic demyelinating neuropathy. ${ }^{[8]}$ There are no RCTs to support the use of IV Ig in paraneoplastic neuropathies, ${ }^{[9]}$ diabetic amyotrophy or radiculoplexopathies, ${ }^{[10,11]}$ vasculitic neuropathies or painful neuropathies associated with Sjögren's syndrome. ${ }^{[12]}$

Based on RCTs, IV Ig (and plasma exchange) is effective in treating acute crises or severe worsening of myasthenia gravis (MG), ${ }^{[13]}$ with clinically relevant effects on average after $4-7$ days. ${ }^{[1]}$ IV Ig shows no effect on mild to severe but stable MG ${ }^{[13]}$ There is no evidence to support the use of IV Ig in inclusion body myositis. Based on one RCT, IV Ig may be considered as additional immunosuppressive therapy in severe or life-threatening dermatomyositis, ${ }^{[14]}$ and probably also in polymyositis despite the absence of RCTs. ${ }^{[12]}$

Although a number of older RCTs using IV Ig in relapsingremitting multiple sclerosis showed a reduction in relapse rates, these effects were not consistently accompanied by a reduction in brain lesions on magnetic resonance imaging. ${ }^{[15]}$ Currently, IV Ig may be indicated to reduce relapses during pregnancy and breastfeeding when the standard disease-modifying drugs are contraindicated. ${ }^{[12]}$ One RCT showed IV Ig was of benefit in severe stiff person syndrome, with benefits lasting between six weeks and one year. ${ }^{[16]}$ In the increasingly 


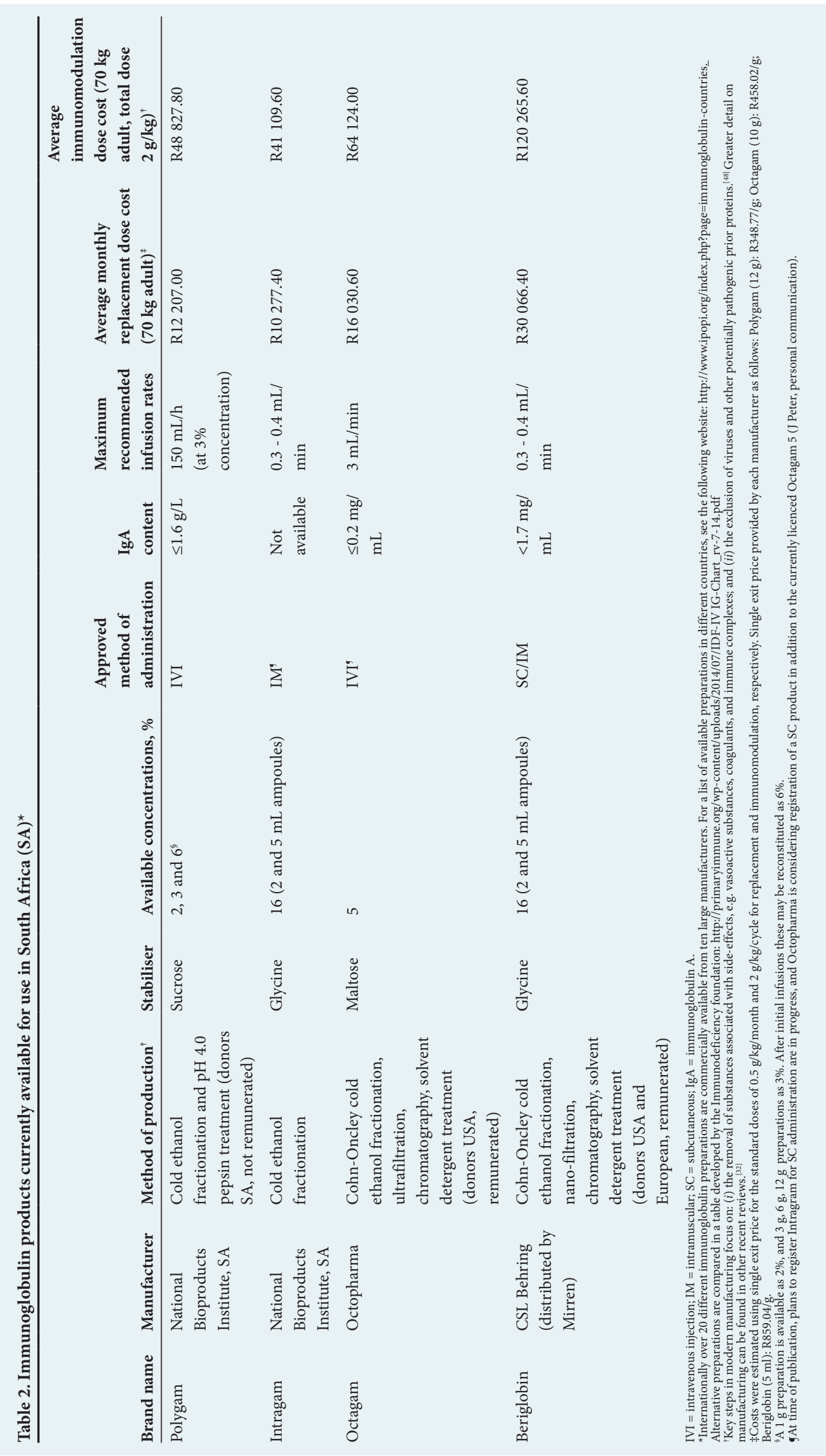

recognised antibody-mediated limbic encephalitis, most frequently due to $\mathrm{N}$-methyl$\mathrm{D}$-aspartate (NMDA)-receptor antibodies, observations from a large cohort $(N=577)$ suggest that steroids as well as plasma exchange or IV Ig may have a place as first-line therapy; about half of the patients responded within four weeks and did not require second-line therapies. ${ }^{[17]}$ One RCT found no efficacy in using IV Ig as add-on therapy in refractory epilepsy when compared with placebo. ${ }^{[18]}$

\section{Haematology}

Treatment with Ig has been found to be useful in a number of haematological disorders. Immune thrombocytopenia (ITP) remains a poorly understood disorder, where antibodies to platelet antigens lead to clinically significant platelet destruction that is not compensated by bone marrow production. The acute presentations are common in children, while chronic forms are dominant in adults. Although the initial treatment of ITP remains corticosteroids (prednisone 1 - $2 \mathrm{mg} / \mathrm{kg}$ ), intravenous immunoglobulin at $0.5-2 \mathrm{~g} / \mathrm{kg}$ has similar efficacy and was found to be cost-effective in children. ${ }^{[19]}$ In adults, immunoglobulin therapy remains a second-line treatment, mainly owing to cost, but is particularly useful to induce a more rapid response in emergency situations (active bleeding, need for procedures or surgery); however, most responses are transient. ${ }^{[20]}$ Overall, the effectiveness of this treatment is similar to that of corticosteroids, which are significantly cheaper. IV Ig is indicated in patients with thrombocytopenia secondary to HIV infection unresponsive to antiretroviral therapy, and the management should not differ from that for the idiopathic form. ${ }^{[21,22]}$

Immune red cell destruction has also been a focus of interest for immunoglobulin therapy. Controlled studies have 
Table 3. Immunoglobulin therapy - adverse reactions ${ }^{\star}$

\begin{tabular}{|c|c|c|c|}
\hline \multirow{2}{*}{$\begin{array}{l}\text { Adverse reaction and frequency } \\
\text { Common }(20-40 \%)\end{array}$} & \multirow[t]{2}{*}{ Severity } & Route of administration & \multirow[t]{2}{*}{ Onset from infusion $^{\dagger}$} \\
\hline & & SC Ig & \\
\hline Infusion site pain, swelling, erythema (up to $75 \%$ in SC Ig) & Usually mild & & Usually immediate \\
\hline Anxiety, malaise, fatigue & Usually mild & & Usually immediate \\
\hline Myalgia, arthralgia, back pain & Usually mild & & Usually immediate \\
\hline Fever, chills, flushing & Usually mild & & Usually immediate \\
\hline Tachycardia, hypo-/hypertension & Usually mild & & Usually immediate \\
\hline Headache & Mild to moderate & IV Ig $\gg>$ SC Ig & Immediate, but can be delayed \\
\hline \multicolumn{4}{|l|}{ Less common $(<5 \%)^{\ddagger}$} \\
\hline Aseptic meningitis & Moderate & IV Ig $\gg>$ SC Ig & Delayed \\
\hline Hyponatraemia & Moderate & IV Ig only & Delayed \\
\hline Neutropenia & Mild/transient & & Delayed \\
\hline Haemolytic anaemia & Moderate to severe & IV Ig $\gg$ SC Ig & Delayed \\
\hline Interference with vaccine effectiveness and/or immunodiagnosis & N/A & IV Ig = SC Ig & N/A \\
\hline Eczema & & IV Ig & Delayed \\
\hline \multicolumn{4}{|l|}{ Rare $(<0.1 \%)$} \\
\hline Anaphylactoid reaction & Severe & IV Ig $\gg>$ SC Ig & Immediate \\
\hline Thrombosis & Severe & IV Ig & Late \\
\hline Blood-borne infectious disease & Severe & IV Ig = SC Ig & N/A \\
\hline Renal impairment & Mild to severe & IV Ig $>$ SC Ig & Delayed \\
\hline \multicolumn{4}{|c|}{$\begin{array}{l}\text { IV Ig = intravenous immunoglobulin therapy; SC Ig = subcutaneous immunoglobulin; } \mathrm{N} / \mathrm{A}=\text { not applicable. } \\
\text { *Frequencies are for patients using long-term therapy. Table modified from Peter and Chapel. } \\
\text { 'Time of onset of adverse reaction from start of infusion, immediate: within } 6 \text { hours; delayed: } 6 \text { hours to } 1 \text { week; late: week to months. } \\
¥ \text { With the exception of anaphylactic reactions, the less common and rare side-effects tend to occur with the higher immunomodulatory doses of immunoglobulin. }\end{array}$} \\
\hline
\end{tabular}

suggested a reduction in parameters of red cell breakdown in $\mathrm{ABO}$ and $\mathrm{Rh}$ haemolytic disease of the newborn, although larger prospective studies are required. ${ }^{[23]}$ Some retrospective data also support its use in fetal red cell alloimmunisation, although a metaanalysis was unable to confirm this. ${ }^{[24]}$ Immunoglobulin therapy was found to be effective in IgG-mediated immune haemolytic anaemia in only $40 \%$ of patients and is not considered as firstline therapy, where corticosteroids are more effective. ${ }^{[25]}$ However, immunoglobulin therapy may be more active in combination with steroids, where a more rapid response is observed. Anecdotal data suggest that the combination was also useful in hyperhaemolysis syndrome associated with sickle cell anaemia in the context of intense red cell breakdown with the non-reactive direct antiglobulin test. ${ }^{[26]}$ Pure red cell aplasia (PRCA) is characterised by severe anaemia with absent maturing red cell precursors in the marrow and reticulocytopenia. Viral infections, particularly B19 parvovirus, are a common cause of PRCA, especially in patients with HIV infection or who are immunosuppressed following organ transplantation. Immunoglobulin therapy is particularly effective in this group at standard doses, with universal responses observed within 90 days of therapy. ${ }^{[27]}$

Immunoglobulin therapy has been recommended in other situations, such as after allogeneic stem cell transplantation for the prevention of cytomegalovirus reactivation, although no controlled studies are available; however, a phase II study and retrospective review by Ichihara et al. ${ }^{[28]}$ showed equal viral reactivation rates compared with the untreated group. Similarly, while anecdotal cases suggested effectiveness in acquired haemophilia or Von Willebrand's disease, review of the available evidence does not support this approach. IV Ig may be reserved for patients with hypogammaglobulinaemia $(\operatorname{IgG}<4 \mathrm{~g} / \mathrm{L})$ after bone marrow transplantation and in adults with secondary antibody deficiency associated with chronic lymphocytic leukaemia and myeloma, ${ }^{[29,30]}$ although its cost-effectiveness has been questioned. ${ }^{[31]}$

\section{Immunology}

Replacement immunoglobulin therapy is life-saving and costeffective for patients with severe hypogammaglobulinaemia/ agammaglobulinaemia owing to primary immunodeficiencies, such as common variable immunodeficiency (CVID) and X-linked agammaglobulinaemia. However, treatment is less clear-cut for the spectrum of borderline hypogammaglobulinaemia, specific antibody deficiency or subclass deficiencies. In these cases, demonstration of absent or declining functional antibody responses, i.e. to test vaccination, in the context of documented ongoing infections, should warrant a 12-month trial of therapy with regular review of clinical response. In long-term replacement therapy, clinicians should focus on two fundamental components: $(i)$ ensuring adequate dosing to prevent infections; and (ii) optimising and monitoring product and patient factors to ensure ongoing compliance, efficacy and safety.

Most national guidelines recommend a starting dose of 400 $600 \mathrm{mg} / \mathrm{kg} / \mathrm{month}$, with higher doses for patients with structural lung damage, e.g. bronchiectasis. ${ }^{[32]}$ Maintenance of adequate serum levels is critical to prevent serious bacterial infections. Pneumonia incidence with IV Ig therapy is five times higher at a trough IgG level of $5 \mathrm{~g} / \mathrm{L}$ compared with $10 \mathrm{~g} / \mathrm{L} .{ }^{[33]}$ A meta-analysis of multiple studies found a $27 \%$ decline in pneumonia incidence for each $1 \mathrm{~g} / \mathrm{L}$ increase in trough $\operatorname{IgG}^{[33]}$ A similar relationship is seen with subcutaneous immunoglobulin (SC Ig) therapy. ${ }^{[34]}$ Ensuring adequate trough levels is cost-effective. ${ }^{[35]}$ Increasingly, clinicians and funders are treating towards a patient's 'biological' trough level which, similar to the normal range of serum IgG in healthy people, 
Table 4. Good practice for the use of immunoglobulin therapy

Initiation of therapy

1. Check baseline renal and liver function, full blood count, and infection screen for hepatitis $\mathrm{B} / \mathrm{C}^{\star}$ and $\mathrm{HIV}^{*}$

2. Anticipate potential side-effects, especially with high-dose IV Ig therapy: older age, cardiovascular disease, procoagulant, and previous reaction to blood products. Select product and preventive measures accordingly

3. Take any baseline specimens, examination findings or photographs required to later document objective response to therapy

4. Store sample of serum for later testing if any questions about infectious agent transmission is raised

5. Consider the planned duration of therapy and product availability to avoid unnecessary future product changes

6. Complete documentation to secure funding for therapy duration

7. Record brand, lot number, dose and reactions with each treatment

8. Ensure adequate pre-hydration; slow first infusion, with incremental increase under supervision

Long-term replacement therapy considerations

1. Patient and clinical factors contribute to the decision on optimal route of administration (IVI, IM or SC), initiation dose (usually 400 - 600 mg/ $\mathrm{kg} / \mathrm{month}$ ) and possible home-based infusions

2. Monitor trough/steady-state IgG levels in immunodeficiency patients every two months initially and then six-monthly. More importantly, review six-monthly to monitor clinical response to treatment, infection burden and problems

3. Discuss and manage patient's expectations and concerns with ongoing therapy, especially if decline in efficacy

4. Remember special situations where modification to treatment may be required, including surgery, hospital admission, pregnancy or travel IV Ig = intravenous immunoglobulin; IVI = intravenous infusion; IM = intramuscular; $\mathrm{SC}=$ subcutaneous.

*Good practice prior to starting any immunosuppressive or immunomuodulatory therapy

recognises that individuals may require differing trough IgG levels to prevent a similar number of infections. At treatment initiation, patients should be reviewed by a medical specialist every 2 - 3 months, with monitoring of efficacy, serum IgG and infusion-related issues, but once treatment has been established six-monthly review is recommended. ${ }^{[32]}$

Chronic therapy with immunoglobulin is expensive, logistically challenging and disruptive to patient lifestyle. To improve long-term compliance, physicians should involve patients and their families early in discussions about route of administration (IV Ig versus SC Ig), timing and location of therapy (clinic-based versus homebased) as well as funding. Involvement of a specialist nurse for home infusion training and follow-up monitoring is important. National patient support groups, such as the Primary Immunodeficiency Network of South Africa (PINSA, http://pinsa.org.za/), offer patients much-needed additional support as well as a role in national advocacy. In SA, the majority of children and adults with primary immunodeficiency receive hospital-based IV Ig replacement therapy, often at suboptimal doses because of cost constraints. However, many developed countries have increasing numbers of immunodeficient patients performing home-based IV Ig or SC Ig therapy. ${ }^{[36]}$ This could potentially be applied in SA, but would require a substantially strengthened specialist nursing and patient support infrastructure to ensure safety and efficacy.

A more in-depth discussion on the issues around immunoglobulin replacement therapy for immunodeficiency has recently been published. ${ }^{[32]}$

\section{Use in other disciplines}

Immunomodulation with IV Ig is also used in a number of other disciplines and specific conditions. In the majority of these it is used as 'rescue' therapy after the failure of first-line treatment, usually consisting of corticosteroids and a steroid-sparing immunosuppressant. In dermatology, IV Ig is used globally for blistering skin diseases. RCT data support the use of IV Ig for steroid-resistant pemphigus and pemphigoid, with a single course of a $0.4 \mathrm{~g} / \mathrm{kg}$ dose for 5 days significantly reducing disease activity. ${ }^{[37]}$ However, although widely used, pooled analysis shows no mortality benefit for use in patients with Stevens-Johnson syndrome/toxic epidermal necrolysis. ${ }^{[38]}$ IV Ig is a well-established first-line therapy for Kawasaki disease to prevent new coronary artery abnormalities, with high-quality evidence supporting use of a single $2 \mathrm{~g} / \mathrm{kg}$ dose within 10 days of symptom onset. ${ }^{[39]}$ Combination with corticosteroids may offer additional benefit. ${ }^{[40]}$ There is limited evidence of benefit in other autoimmune vasculitides, or catastrophic antiphospholipid syndrome, and IV Ig is not currently recommended over less expensive therapy ${ }^{[41]}$ Large numbers of studies have examined the use of IV Ig and IgM-enriched immunoglobulin preparations for the treatment of severe bacterial sepsis and septic shock, and pooled data fail to show a mortality benefit. ${ }^{[42]}$ In preterm (<37 weeks) and low-birthweight infants, IV Ig replacement can decrease sepsis and serious infection (by only $3-4 \%$ ), with no mortality benefit. ${ }^{[43,44]}$ In limited resource settings, such as the SA public sector, these small benefits are insufficient to justify routine use.

\section{Conclusions}

Immunoglobulin therapy is an expensive and complex therapy that can be lifesaving. To ensure that SA patients access therapy appropriately, clinicians must be well informed on the available evidence base to motivate successfully. As many of these conditions are uncommon, clinicians who do not regularly prescribe immunoglobulins need to be aware of important product and patient factors guiding safe and effective use. It is hoped that this article serves as an effective interim measure during the ongoing development of formal SA immunoglobulin therapy guidelines to improve and advocate access and appropriate use.

\section{References}

Berger M, McCallus DE, Lin CS. Rapid and reversible responses to IV Ig in autoimmune neuromuscula diseases suggest mechanisms of action involving competition with functionally important autoantibodies. J Peripher Nerv Syst 2013;18(4):275-296. [http://dx.doi.org/10.1111/jns5.12048]

. Schwab I, Nimmerjahn F. Intravenous immunoglobulin therapy: How does IgG modulate the immune system? Nat Rev Immunol 2013;13(3):176-189. [http://dx.doi.org/10.1038/nri3401]

3. Gelfand EW. Intravenous immune globulin in autoimmune and inflammatory diseases. N Engl J Med 2012;367(21):2015-2025. [http://dx.doi.org/10.1056/NEJMra1009433] 
4. Jolles S, Sewell WA, Misbah SA. Clinical uses of intravenous immunoglobulin. Clin Exp Immunol 2005;142(1):1-11. [http://dx.doi.org/10.1111/j.1365-2249.2005.02834.x]

5. Hughes RA, Swan AV, van Doorn PA. Intravenous immunoglobulin for Guillain-Barre syndrome Cochrane Database Syst Rev 2012;(7):CD002063. [http://dx.doi.or/10.1002/14651858.CD002063.pub5] 6. Eftimov F, Winer JB, Vermeulen M, de Haan R, van Schaik IN. Intravenous immunoglobulin for chronic inflammatory demyelinating polyradiculoneuropathy. Cochrane Database Syst Rev 2013; (12):CD001797. [http://dx.doi.org/10.1002/14651858.CD001797.pub3]

7. Van Schaik IN, van den Berg LH, de Haan R, Vermeulen M. Intravenous immunoglobulin for multifocal motor neuropathy. Cochrane Database Syst Rev 2005;(2):CD004429.

8. Hughes RA, Lunn MP. Neuromuscular disease: IV Ig for neuromuscular disease - effective but expensive. Nat Rev Neurol 2012;8(6):303-305. [http://dx.doi.org/10.1038/nrneurol.2012.92]

9. Giometto B, Vitaliani R, Lindeck-Pozza E, Grisold W, Vedeler C. Treatment for paraneoplastic neuropathies. Cochrane Database Syst Rev 2012;(12):CD007625. [http://dx.doi.org/10.1002/14651858. CD007625.pub2]

10. Chan YC, Lo YL, Chan ES. Immunotherapy for diabetic amyotrophy. Cochrane Database Syst Rev 2012;(6):CD006521. [http://dx.doi.org/10.1002/14651858.CD006521.pub3

11. Patwa HS, Chaudhry V, Katzberg H, Rae-Grant AD, So YT. Evidence-based guideline: Intravenous immunoglobulin in the treatment of neuromuscular disorders: Report of the Therapeutics and Technology Assessment Subcommittee of the American Academy of Neurology. Neurology 2012;78(13):1009-1015. [http://dx.doi.org/10.1212/WNL.0b013e31824de293]

12. Yiannopoulou KG. Intravenous Immunoglobulins in Neurological Diseases: Established and Novel Clinical Applications. INTECH Open Access Publisher, 2011.

13. Gajdos P, Chevret S, Toyka KV. Intravenous immunoglobulin for myasthenia gravis. Cochran Database Syst Rev 2012;(12):CD002277. [http://dx.doi.org/10.1002/14651858.CD002277.pub4]

14. Gordon PA, Winer JB, Hoogendijk JE, Choy EH. Immunosuppressant and immunomodulator treatment for dermatomyositis and polymyositis. Cochrane Database Syst Rev 2012;(8):CD003643. [http://dx.doi.org/10.1002/14651858.CD003643.pub4]

15. Gray O, McDonnell GV, Forbes RB. Intravenous immunoglobulins for multiple sclerosis. Cochrane Database Syst Rev 2003;(4):CD002936.

16. Hadavi S, Noyce AJ, Leslie RD, Giovannoni G. Stiff person syndrome. Pract Neurol 2011;11(5):272 282. [http://dx.doi.org/10.1136/practneurol-2011-000071]

17. Titulaer MJ, McCracken L, Gabilondo I, et al. Treatment and prognostic factors for long-term outcome in patients with anti-NMDA receptor encephalitis: An observational cohort study. Lancet Neurol 2013;12(2):157-165. [http://dx.doi.org/10.1016/S1474-4422(12)70310-1]

18. Walker L, Pirmohamed M, Marson AG. Immunomodulatory interventions for focal epilepsy syndromes. Cochrane Database Syst Rev 2013;(96):CD009945. [http://dx.doi.org/10.1002/1465185 CD009945.pub2]

19. Blackhouse G, Xie F, Levine MA, et al. Canadian cost-utility analysis of intravenous immunoglobulin for acute childhood idiopathic thrombocytopenic purpura. J Popul Ther Clin Pharmacol 2012;19(2):e166-178

20. Qin YH, Zhou TB, Su LN, Lei FY, Zhao YJ, Huang WF. The efficacy of different dose intraveno immunoglobulin in treating acute idiopathic thrombocytopenic purpura: A meta-analysis of 13 randomized controlled trials. Blood Coagul Fibrinolysis 2010;21(8):713-721.

21. Jahnke L, Applebaum S, Sherman LA, Greenberger PA, Green D. An evaluation of intravenous immunoglobulin in the treatment of human immunodeficiency virus-associated thrombocytopenia. Transfusion 1994;34(9):759-764. [http://dx.doi.org/10.1046/j.1537-2995.1994.34994378275.x]

2. Scaradavou A. HIV-related thrombocytopenia. Blood Rev 2002;16(1):73-76. [http://dx.doi. org/10.1054/blre.2001.0188

23. Alcock GS, Liley H. Immunoglobulin infusion for isoimmune haemolytic jaundice in neonates. Cochrane Database Syst Rev 2002;(3):CD003313

24. Wong KS, Connan K, Rowlands S, Kornman LH, Savoia HF. Antenatal immunoglobulin for feta red blood cell alloimmunization. Cochrane Database Syst Rev 2013:(5):CD008267. [http://dx.dol org/10.1002/14651858.CD008267.pub2

25. Flores G, Cunningham-Rundles C, Newland AC, Bussel JB. Efficacy of intravenous immunoglobulin in the treatment of autoimmune hemolytic anemia: Results in 73 patients. Am J Hematol 1993:44(4):237242. [http://dx.doi.org/10.1002/ajh 2830440404] 26. Win N, Sinha S, Lee E, Mills W. Treatment with intravenous immunoglobulin and steroids may correct Med Rev 2010;24(1):64-67. [http://dx.doi.org/10.1016/j.tmrv.2009.09.006]

27. Koduri PR. Parvovirus B19-related anemia in HIV-infected patients. AIDS Patient Care STDs 2000;14(1):7-11. [http://dx.doi.org/10.1089/108729100318082]
28. Ichihara $\mathrm{H}$, Nakamae $\mathrm{H}$, Hirose $\mathrm{A}$, et al. Immunoglobulin prophylaxis against cytomegalovirus infection in patients at high risk of infection following allogeneic hematopoietic cell transplantation. Transplant Proc 2011;43(10):3927-3932. [http://dx.doi.org/10.1016/j. transproceed.2011.08.10]

29. Chapel HM, Lee M, Hargreaves R, Pamphilon DH, Prentice AG. Randomised trial of intravenou immunoglobulin as prophylaxis against infection in plateau-phase multiple myeloma. The UK Group for Immunoglobulin Replacement Therapy in Multiple Myeloma. Lancet 1994:343(8905):1059-1063. [http://dx.doi.org/10.1016/S0140-6736(94)90180-5]

30. Gamm H, Huber C, Chapel H, Lee M, Ries F, Dicato MA. Intravenous immune globulin in chronic ymphocytic leukaemia. Clin Exp Immunol 1994;97(Suppl 1):17-20.

31. Weeks JC, Tierney MR, Weinstein MC. Cost effectiveness of prophylactic intravenous immun globulin in chronic lymphocytic leukemia. N Engl J Med 1991;325(2):81-86. [http://dx.doi. org/10.1056 NEJM199107113250202]

32. Peter JG, Chapel H. Immunoglobulin replacement therapy for primary immunodeficiencies Immunotherapy 2014;6(7):853-869. [http://dx.doi.org/10.2217/imt.14.54]

33. Orange JS, Grossman WJ, Navickis RJ, Wilkes MM. Impact of trough IgG on pneumonia incidence in primary immunodeficiency: A meta-analysis of clinical studies. Clin Immunol 2010;137(1):21-30. [http://dx.doi.org/10.1016/..clim.2010.06.012]

34. Lingman-Framme J, Fasth A. Subcutaneous immunoglobulin for primary and secondary immunodeficiencies: An evidence-based review. Drugs 2013;73(12):1307-1319. [http://dx.do. org/10.1007/s40265-013-0094-3]

35. Modell V, Gee B, Lewis DB, et al. Global study of primary immunodeficiency diseases (PI) - diagnosis treatment, and economic impact: An updated report from the Jeffrey Modell Foundation. Immun Res 2011;51(1):61-70. [http://dx.doi.org/10.1007/s12026-011-8241-y]

36. Chapel $\mathrm{H}$, Brennan V, Delson E. Immunoglobulin replacement therapy by self-infusion at home. Clin Exp Immunol 1988;73(1):160-162

37. Gurcan HM, Jeph S, Ahmed AR. Intravenous immunoglobulin therapy in autoimmune mucocutaneous blistering diseases: A review of the evidence for its efficacy and safety. Am J Clin Dermatol 2010;11(5):315-326. http://dx.doi.org/10.2165/11533290-000000000-00000]

38. Lee HY, Lim YL, Thirumoorthy T, Pang SM. The role of intravenous immunoglobulin in toxi epidermal necrolysis: A retrospective analysis of 64 patients managed in a specialized centre. $\mathrm{Br}$ Dermatol 2013;169(6):1304-1309. [http://dx.doi.org/10.1111/bjd.12607]

39. Oates-Whitehead RM, Baumer JH, Haines L, et al. Intravenous immunoglobulin for the treatment of Kawasaki disease in children. Cochrane Database Syst Rev 2003;(4):CD004000

40. Chen S, Dong Y, Yin Y, Krucoff MW. Intravenous immunoglobulin plus corticosteroid to preven coronary artery abnormalities in Kawasaki disease: A meta-analysis. Heart 2013;99(2):76-82. [http:// dx.doi.org/10.1136/heartinl-2012-302126]

41. Wu CQ, Kustec VE, Brown RN, Martin MC, Filion KB. The medical management of antiphospholipid syndrome in pregnancy: A meta-analysis. Obstet Gynecol 2014;123(Suppl 1):178S-179S. [http:/ dx.doi.org/10.1097/01.AOG.0000447195.12926.b9

42. Laupland KB, Kirkpatrick AW, Delaney A. Polyclonal intravenous immunoglobulin for the treatment of severe sepsis and septic shock in critically ill adults: A systematic review and meta-analysis. Cr Care Med 2007;35(12):2686-2692. [http://dx.doi.org/10.1097/01.CCM.0000295312.13466.1C]

43. Ohlsson A, Lacy JB. Intravenous immunoglobulin for preventing infection in preterm and/or low birth weight infants. Cochrane Database Syst Rev 2013;(7):CD000361.

44. Ohlsson A, Lacy JB. Intravenous immunoglobulin for suspected or proven infection in neonates. Cochrane Database Syst Rev 2013;(7):CD001239.

45. Orange JS, Hossny EM, Weiler CR, et al. Use of intravenous immunoglobulin in human disease: A review of evidence by members of the Primary Immunodeficiency Committee of the American Academy of Allergy, Asthma and Immunology. J Allergy Clin Immunol 2006;117(4 Suppl):S525-553. [http://dx.doi.org/10.1016/.j.jaci.2006.01.015]Cite

46. Dhalla F, Lucas M, Schuh A, et al. Antibody deficiency secondary to chronic lymphocytic leukemi Should patients be treated with prophylactic replacement immunoglobulin? I Clin Immuno 2014;34(3):277-282. [http://dx.doi.org/10.1007/s10875-014-9995-5]

47. Guyatt GH, Oxman AD, Vist GE, et al. GRADE: An emerging consensus on rating quality of evidence and strength of recommendations. Br Med J 2008:336(7650):924-926. [http://dx.doi.org/10.1136/ bmj.39489.470347.AD]

48. Poelsler G, Berting A, Kindermann J, et al. A new liquid intravenous immunoglobulin with three dedicated virus reduction steps: Virus and prion reduction capacity. Vox Sang 2008:94(3):184-192. [http://dx.doi.org/10.1111/j.1423-0410.2007.01016.x] 